\title{
A materialidade epistolar. $O$ que nos dizem os manuscritos autógrafos
}

\author{
[ The epistolary materiality. What the autograph manuscripts tell us
}

\begin{abstract}
Alain Pagès ${ }^{\mathrm{I}}$
Tradução de Ligia Fonseca Ferreira (Unifesp).
\end{abstract}

\begin{abstract}
RESUMO - Quando a reprodução fac-similar não é possível, as edições de correspondências propõem aos leitores um texto impresso, sem levar em conta tudo o que remete à aparência dos manuscritos autógrafos. Em geral, tais aspectos materiais são portadores de informações de fundamental relevância no que diz respeito à maneira como um endereço é redigido no envelope; ao movimento da escrita e da forma dos caracteres; ao desenho da assinatura; às indicações contidas nas zonas periféricas das cartas, as margens ou cabeçalhos. Neste artigo, pretende-se analisar esses diversos elementos à luz de um objeto privilegiado - a correspondência d’Émile Zola. Os exemplos examinados mostram que, em todos os casos, é extremamente produtivo retornar ao manuscrito original e reexeminá-lo, pois o documento oferece informações que o mero conhecimento do texto impresso quase nunca fornece. PALAVRAS-CHAVE-Émile Zola; manuscrito autógra-
\end{abstract}

fo; correspondência; comunicação epistolar. • ABSTRACT - Correspondence editions, when facsimile reproductions are not possible, provide readers written texts, besides all that the appearance of autographed manuscripts contain. Generally, such material aspects sustain information of utmost importance: on how the address is written in an envelope, movement of the writing and character format, design of the signature, notes on the boarder of the letters, margins or headings. In the present article we aim to analyze those various elements in light of a privilege object - the correspondence of Emile Zola. The examined samples indicate that in all cases it is extremely productive to go back to the original manuscripts and reexamine them since the documents offer information that the mere knowledge of the written text almost never provides. • KEYWORDS - Émile Zola; autograph manuscript; correspondence; epistolary communication

Recebido em I7 de julho de 2017

Aprovado em 30 de julho de 2017

PAGÈS, Alain. A materialidade epistolar. O que nos dizem os manuscritos autógrafos. Revista do Instituto de Estudos Brasileiros, Brasil, n. 67, p. Io6-I23, ago. 2017.

DOI: http://dx.doi.org/Io.II606/issn.23I6-90IX.voi67pIo6-I23

I Université Sorbonne Nouvelle Paris 3. 
Embora indiquem com precisão a origem do corpus a que se referem, a maioria das edições de correspondência apagam, no texto impresso que produzem, a materialidade do manuscrito autógrafo. É absolutamente normal. As edições têm como objetivo transcrever um manuscrito, transformar em obra coerente o que só existia, orginalmente, sob a forma de folhas dispersas. No entanto, todos aqueles que se dedicaram ao trabalho de edição sabem que uma perda considerável resulta do efeito de neutralização provocado pela forma impressa. O que se perde é o próprio aspecto do manuscrito, o poder de sedução que possuem uma escrita e folhas que exalam cheiro de um arquivo antigo que se preservou do desaparecimento graças aos cuidados de uma conservação escrupulosa ou, ainda, graças ao acaso de alguma milagrosa transmissão. É, portanto, difícil compreender a emoção sentida por um colecionador, a paixão que o leva, às vezes, a fazer aquisições pouco razoáveis, sem levar em conta o que revelam os manuscritos autógrafos - essa forma particular de discurso que sussurra coisas em nossos ouvidos.

No caso de uma correspondência, essa questão é de suma importância, pois uma carta comunica sua mensagem não somente pelo texto que propõe, mas também pela multiplicidade dos signos que acompanham o texto: a forma da escrita, a ocupação do espaço da página, o número de folhas, os acréscimos colocados nas margens, a assinatura etc. Neste artigo, pretendemos interrogar esses signos, que compõem o discurso da materialidade epistolar, tomando como exemplo a correspondência de Émile Zola. O corpus editado até o momento (cerca de 5.200 cartas) divide-se em dois conjuntos: a correspondência geral, composta de II volumes²; e a correspondência íntima em dois volumes, contendo as cartas que o escritor enviou às duas mulheres

2 ZOLA, Émile. Correspondance. [Correspondência.] Organização de Bard H. Bakker. Montréal: Les Presses de l'Université de Montréal; Paris: Éditions du CNRS, I978-I995. Io v.; ZOLA, Émile. Correspondance XI. Lettres retrouvées (I858-I902). Apresentação de Owen Morgan e Dorothy E. Speirs. Montréal: Les Presses del' Université de Montréal; Paris: CNRS Éditions, 2010. 
com as quais compartilhou sua existência, Alexandrine e Jeanne 3 . O conjunto dos manuscritos autógrafos da correspondência íntima foi conservado; logo, é possível referir-se a eles. Quanto à correspondência geral, é formada por documentos dos quais em geral só existe fonte impressa (os originais foram perdidos ou não se encontram disponíveis para consulta), mas o número de manuscritos de cartas ainda acessíveis permanece expressivo: estima-se que correspondam a 70\% do conjunto, ao passo que $30 \%$ das cartas conhecidas originam-se de texto impresso.

\section{O ENVELOPE}

Comecemos por ele. $\mathrm{O}$ envelope contém a carta. Fina barreira de papel que protege o segredo da comunicação. Abrimos para descobrir o texto ali contido. Mas, tal qual, antes mesmo de ser deslacrado, o envelope entrega uma mensagem à pessoa que o segura nas mãos: a escrita, o nome, o endereço redigido ou não de forma completa. Em se tratando do futuro editor (caso tenha ele a sorte de dispor desse precioso documento, muitas vezes lamentavelmente destruído), uma indicação essencial é fornecida pelo carimbo postal quanto este registra uma data às vezes ausente da própria carta manuscrita.

Será que as linhas inscritas no retângulo do envelope (também chamado de "sobrescrito" - etimologicamente "a escrita em cima"...) não poderiam ser consideradas como introdução da carta? No entanto, essas linhas são sistematicamente apagadas de todas as edições de correspondência. Quando Zola passa uma temporada em sua casa de campo na cidade de Médan, situada a 40 quilômetros de Paris, seus correspondentes contentam-se em escrever no envelope o nome do escritor, seguido de "Médan, Seine-et-Oise”. A indicação do vilarejo e do departamento 4 basta. Nenhuma menção ao nome da rua é necessária, pois aquela cidadezinha às margens do Sena ganhou fama, desde então, graças à glória do romancista que escolhera viver ali uma parte do ano.

Existem envelopes misteriosos cujo sobrescrito constitui um verdadeiro enigma. Veja-se o caso do envelope (Figura I) que corresponde à primeira das cartas de Zola a Jeanne Rozerot no corpus sobre o qual já nos debruçamos.

3 Idem. Lettres à Jeanne Rozerot. [Cartas a Jeanne Rozerot] (I892-I902). Edição preparada por Brigitte Émile-Zola e Alain Pagès. Paris: Gallimard, 2004; Idem. Lettres à Alexandrine [Cartas a Alexandrine] (I876-I90I). Edição preparada por Brigitte Émile-Zola e Alain Pagès. Paris: Gallimard, 20I4. Alexandrine é esposa do escritor; Jeanne Rozerot é a mãe de seus dois filhos, Denise e Jacques, nascidos da relação extraconjugal iniciada em I888, quando o autor tinha 48 anos.

4 Seine-et-Oise foi um dos 83 "departamentos" da França, sudivisões territoriais e eleitorais criadas em I789, durante a Revolução Francesa. Hoje, o número de departamentos eleva-se a IOI. (N.T.) 


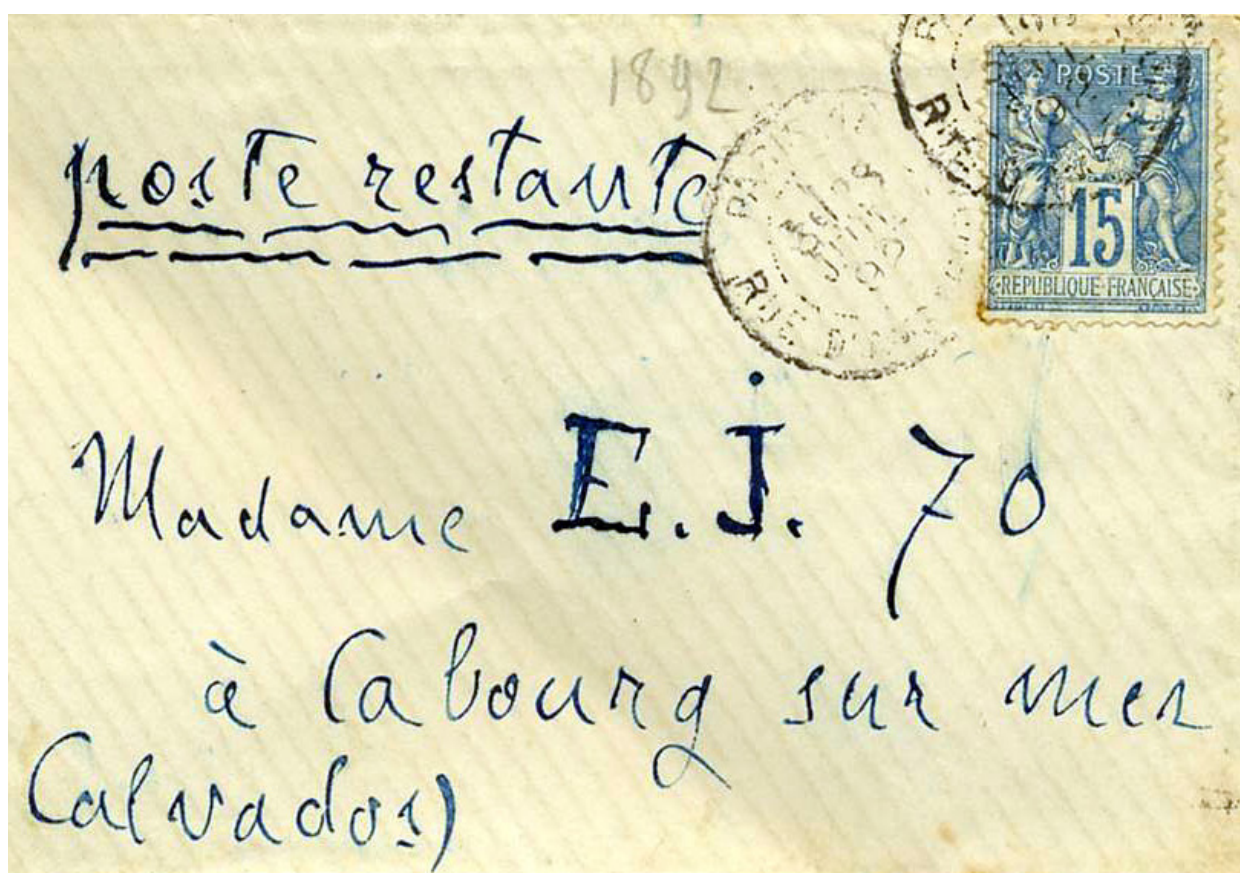

Figura I - (c) Centro Zola, Item, CNRS

poste restante

Madame E. J. 70

à Cabourg sur mer (Calvados)

[posta-restante

Senhora E. J. 70

em [Cabourg-sur-mer] ([departamento] Calvados)]

Datada de 28 de julho de I892, a carta contida no envelope é endereçada, posta-restante, na cidade de Cabourg [Normandia], onde Jeanne se refugiou com seus filhos. Zola lhe havia pedido para se afastar de Paris, receando que o ciúme de sua esposa, Alexandrine, pudesse atingir as crianças, pois, naquele momento, o casal atravessava a crise mais violenta de sua existência.

O que significam as iniciais “E. J.”? Não é difícil adivinhar que correspondem aos nomes dos dois amantes: "Émile - Jeanne". Jeanne Rozerot torna-se, assim, "Madame Émile Jeanne". E por que essas iniciais são seguidas do número "70”? Zola, que era supersticioso, gostava particularmente do número "7", mas isso não explica tudo. Para encontrar a chave desse enigma, é necessário pensar numa data. O número inscrito refere-se ao ano de nascimento de Jeanne (I867) e ao de Émile (I840); combinando-se os últimos algarismos das duas datas, chega-se ao resultado " 70 ". Uma outra razão para essa adição origina-se no fato de tanto Zola como Jeanne terem nascido no mês de abril. A fusão dos números extraídos das datas de nascimento leva à criação de um número mítico, um talismã simbolizando a união selada entre ambos. 


\section{A GRAFIA}

É pelo encantamento de sua escrita, antes mesmo de ser decifrada, que uma carta se oferece ao olhar. A beleza de um manuscrito autógrafo reside, acima de tudo, em sua aparência escritural. Como um rosto que convida à contemplação, essa beleza compõe-se de diversos parâmetros: a regularidade ou a irregularidade das linhas, o legível ou o ilegível, os caracteres estreitos ou mais espaçados, a tinta mais fosca ou nítida, a cor (preta, vermelha ou azul)... Os manuscritos autógrafos mais notáveis são aqueles que mantiveram, a despeito dos anos passados, uma parte de juventude: guardaram todo o seu frescor.

Por que colecionar manuscritos autógrafos? "Uma escrita fala ou não fala com você”, responde François Labadens, refletindo sobre uma atividade à qual dedicou toda a sua existência. Uma coleção, explica ele, só existe se estiver fundamentada em escolhas muito precisas. Os escritores selecionados para alimentar a coleção são comparáveis a heróis ou heroínas de romance pelos quais o colecionador se apaixonou e cujo destino ele queria acompanhar, reconstituindo a existência desses indivíduos. Aliás, pouco importam as reticências ideológicas sentidas em relação ao conteúdo de algumas obras. Uma atração inexplicável, que emana do poder da sedução, bem como a busca de uma intimidade privilegiada com os autores dos manuscritos pacientemente reunidos, encontra-se na base da seleção realizada:

Há evidentemente um primeiro nível de sedução, de ordem puramente estética. O poder do traço. Uma escrita que fala ou não fala com você. A condessa de Martel, também conhecida como Gyp, escrevia seus romances [...] e lançava anátemas antissemitas numa vigorosa escrita com tinta roxa, forjada pelas freiras do Sagrado Coração de Nancy, que tornava simpática aquela mulher. O fuinha Léon Bloy murmurava suas maldades através de uma grafia de sacristão, e o taciturno Barbey d’Aurevilly enriquecia a sua, inspirada no século XVII, com tintas verdes, vermelhas, azuis...

Organizar um manuscrito prolonga esse sentimento muito particular de atração. O modo como Émile Zola preenche sua página, num de seus três formatos de papel favoritos, manifesta bem o investimento - a conquista - do espaço pela ideia, de uma escrita quadrada, com tinta grossa, com letras ligadas de forma variada, dependendo dos diferentes momentos da sua vida5.

Mesmo quando não diz nada, um documento autógrafo possui um valor que lhe é próprio: a autenticidade da escrita. É o que mostra o cartão de visita escrito por Zola (Figura 2).

5 LABADENS, François. Cet obscur objet du désir. Propos d'un amateur d'autographes. [Este obscuro objeto do desejo. Entrevista com um amante de manuscritos autógrafos.] In: L'entreprise et sa mémoire. Mélanges en l'honneur de Maurice Hamon. Organização de Didier Bondue. Paris: Presses Universitaires de Paris-Sorbonne, 20I2, p. 236. 


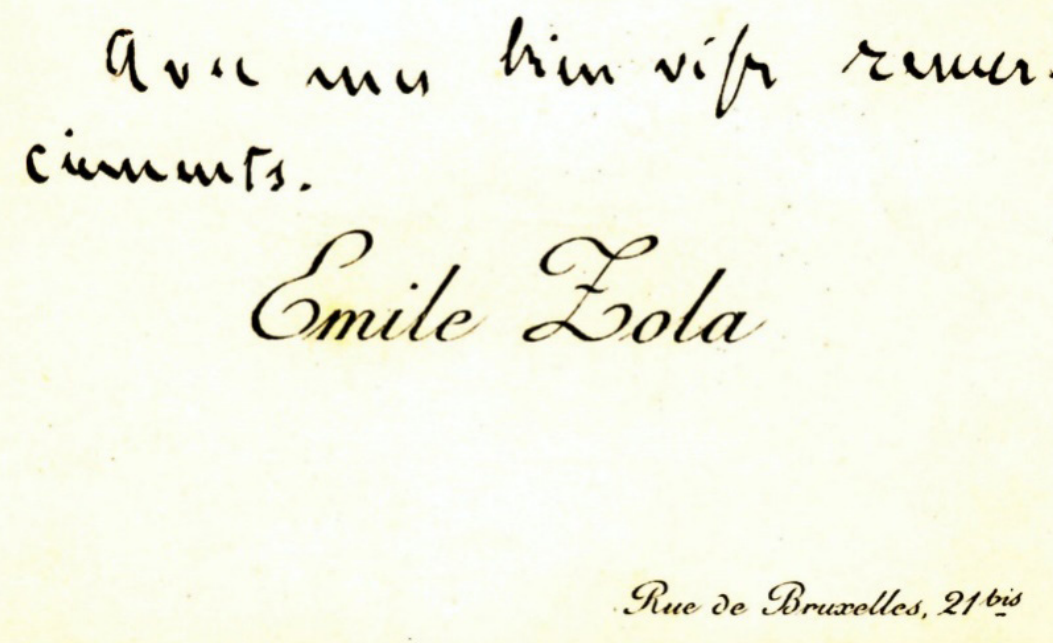

Figura 2 - (C) Coleção particular

Avec mes bien vifs remerciements

[Com meus mais vivos agradecimentos].

Nada. Nenhuma informação, nenhuma referência cronológica, nenhum fato ao qual se possa associar algumas palavras, repetidas tantas vezes em outros cartões de visita semelhantes a esse: "Com meus mais vivos agradecimentos". Um texto tão insignificante que é impossível incluí-lo na edição da correspondência do escritor, pois não é possível colocá-lo num lugar qualquer da sequência ordenada que rege a progressão editorial. Entretanto, algo de insubstituível se manifesta aí: uma presença, a firmeza de uma escrita, a mão criadora do escritor voltada para um amigo ou pessoa próxima a quem expressa os agradecimentos.

O corpo do escritor fica marcado na escrita. No caso de Zola, essas palavras cuidadosamente caligrafadas, com letras arredondadas, esmagadas pela pluma que as traçou, ocupando todo o espaço necessário sobre a folha de papel. As rasuras raramente interrompem o fluxo de uma escrita que não deseja nada dissimular e almeja, antes de mais nada, ser legível. Zola adotara um lema latino que ficou célebre. O escritor mandou pintá-lo no manto da lareira situada em seu gabinete, em Médan: "nulla dies sine linea". A sentença remonta à mais alta Antiguidade. Plínio, o Velho a menciona em sua História natural e a atribui ao pintor grego do século IV a. C., Apeles. Se desenvolvemos seu conteúdo, significa: "nenhum dia sem traçar uma linha com o pincel". Compreende-se, pois, como se aplica a um escritor. Cada linha conta. Assim como acontece quando se levanta um muro, para construir uma obra é preciso sobrepor continuamente tijolo por tijolo. Não se pode perder o que se acaba de escrever, pois será preciso retrabalhar o texto e avançar. De onde a necessidade de uma perfeita legibilidade, para si e para os outros. Quando um desenvolvimento emperra numa sintaxe confusa, quando as linhas não são claramente dispostas no 
quadro da página, Zola prefere rasgar a folha de papel na qual escrevia, pegar outra e recomeçar. Nenhum dia sem redigir uma nova página.

O ESPAÇO ESCRITURA

Uma carta é um quadro e, em uma página, tem o poder de entregar o conteúdo total da mensagem, segundo uma disposição gráfica que lhe é própria. Veja-se, por exemplo, a carta escrita por Zola, em 2 de dezembro de I884, a seu editor, Georges Charpentier (Figura 3).

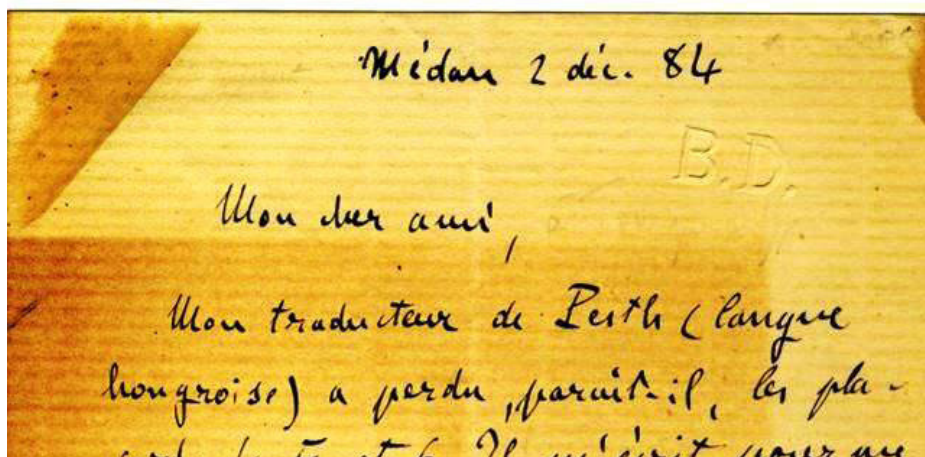

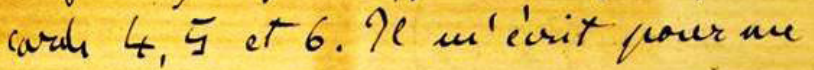
lupplier de lui envayer un don.

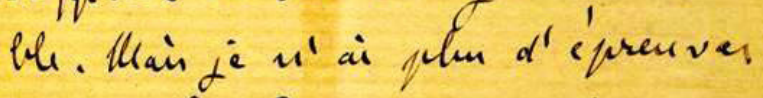
dirforither. Oe vour en pris, en: voyer lui immédiatement ber plararde en yuertion, vom olevy ler avois, ct voun bs ferey rePive pour vom, d'il le fant.

$$
\text { adresse: M.M. Révai }
$$

frères, editenri, à Frith (Alongrie) Herci, et affectuenement à vou tom.

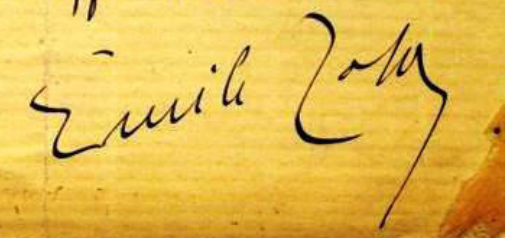

Figura 3 - (c) Coleção particular (carta inédita)

II2 [

revista do Instituto de Estudos Brasileiros • n. 67 • ago. 2017 (p. IO6-I23) 
Mon cher ami,

Mon traducteur de Pesth (langue hongroise) a perdu, paraît-il, les placards 4, 5 et 6. Il m'écrit pour me supplier de lui envoyer un double. Mais je n'ai plus d'épreuves disponibles. Je vous en prie, envoyez-lui immédiatement les placards en question; vous devez les avoir, et vous les ferez retirer pour vous, s'il le faut.

Adresse: M.M. Révai frères, éditeurs, à Pesth (Hongrie).

Merci, et affectueusement à vous tous.

Émile Zola

[Meu caro amigo,

Meu tradutor de Pesth (língua húngara) perdeu, ao que parece, as provas 4, 5 e 6. Escreveu-me suplicando para lhe enviar uma cópia. Mas não tenho mais nenhuma disponível. Por gentileza, envia-lhe imediatamente as provas solicitadas; deves tê-los e mandarás reimprimi-los para ti, se for necessário.

Endereço: M.M. Révai irmãos, editores, em Pesth (Hungria).

Obrigado, e afetuosamente a todos.

Émile Zola].

Trata-se das provas de Germinal, então publicado como folhetim no periódico Gil Blas enquanto se faziam traduções em língua estrangeira na maioria dos países europeus. Curta, com objetivo preciso, essa carta se inscreve na sequência cronológica dos anos I884-I885, mas só ganha sentido se consideradas outras missivas do período, também relacionadas à publicação do romance, as quais ela enriquece com o valor de sua mensagem, participando, assim, da elaboração do gigantesco puzzle das informações contidas na correspondência.

Notem-se os princípios que norteiam a organização do quadro gráfico. O local e a data indicados na primeira linha, à direita da página. No início, o vocativo amistoso: "Meu caro amigo". No final da carta, a fórmula de despedida: "Obrigado, e afetuosamente a todos". E, por fim, destaca-se do resto a assinatura, que sobe em diagonal no lado direito da página e, com caracteres ampliados, termina preenchendo o espaço escritural, sem deixar nenhum espaço vazio.

Aparecem, assim, duas zonas textuais: o texto livre, que contém a mensagem da carta; e o texto codificado, que rege a forma de envio (data, destinatário, fórmula de polidez final). Por convenção implícita, os editores de correspondência penduram suas anotações no texto livre e desprezam o resto. Tendem igualmente a ignorar as saudações e fórmulas de despedida, como se o fato de serem corriqueiras dispensasse qualquer comentário. Porém, é sempre recomendável examiná-las com atenção. No 
presente caso, a menção “a todos” mereceria uma nota: ao terminar a carta, Zola dirige-se a seu editor, pensando na família deste à qual estende seus afetuosos cumprimentos pela aproximação do Natal.

\section{A data}

A data não representa apenas uma indicação cronológica, permitindo situar uma carta na continuidade fatual. Trata-se igualmente de um gesto performativo. É realmente notável, na correspondência de Zola, a menção regular às datas e locais no cabeçalho das cartas. Obviamente, existem textos não datados, mas são relativamente raros.

A preocupação com a data tem um papel particularmente importante na correspondência íntima, especialmente nas cartas que Zola escreve a sua esposa, Alexandrine Zola, entre I895 e I897, quando ela faz viagens pela Itália. Nesse período, o escritor firmou uma espécie de contrato moral com a esposa. Ela aceitou a relação extraconjugal com Jeanne, mas, em troca do acordo, poderá percorrer e descobrir o país vizinho, fazer amigos, ter uma vida independente de mulher livre, como uma espécie de compensação pelo drama que quase os levou à separação definitiva. Assim, Alexandrine encontra uma saída para deixar o marido, tendo a viagem como pretexto. No entanto, ele não se afasta, não a abandona e permanecerá fiel. Mas como? Através das cartas que escreve todos os dias à noite. E o que dizem essas mensagens? Que ele se encontra, à noite, no apartamento parisiense da rua de Bruxelas, endereço de seu gabinete de trabalho, que pensa na esposa e deve lhe fazer um relatório preciso das atividades realizadas durante o dia. E essas mensagens também dizem que ele não dorme na casa de Jeanne. Os serviçais que atendem o romancista garantem o respeito ao código social. Submetido a esse controle externo, Zola encontra-se, pois, impossibilitado de passar a noite fora de seu domicílio. Ao escrever à mulher sempre à noite, o escritor lhe demonstra sua fidelidade. As datas colocadas no cabeçalho de cada carta assinalam que o pacto está sendo respeitado. Por essa razão, Zola informa-se escrupulosamente sobre os deslocamentos realizados por Alexandrine, mantendo-se a par das cidades que ela visitará a fim de que as cartas lhe cheguem sem falta. E, quando algumas cartas se perdem, o escritor se preocupa, se aflige e faz tudo para tranquilizar sua destinatária, como mostram essas linhas, escritas às pressas, em 2 de novembro de I895, num cartão de visita:

Querida esposa, recebo tua carta de Aix e angustia-me saber que uma de minhas cartas não te chegou. Escrevo todos os dias, e escreverei todos os dias, aconteça o que acontecer. Aceito, pois, tua reclamação. - Envio este bilhete para dizer-te isso. Hoje à noite, escreverei mais longamente e responderei a tua carta do dia 3I que acabo de receber (são 2hI5). Beijo-a com carinho'.

Zola multiplica a remessa de mensagens: um bilhete, anterior ao cartão de

6 ZOLA, Émile. Lettres à Alexandrine, op. cit., p. 68. 
visita, avisa que outra carta chegará! O diário epistolar redigido para Alexandrine, enquanto ela se encontra viajando no exterior, acompanha-se de uma obsessão pela cronologia. Cada dia que se vai corresponde à data de uma carta enviada à esposa.

Quando se aborda uma correspondência assim marcada pelo envio regular de uma carta por dia, situá-la no tempo é uma tarefa de fundamental importância. No limite, o essencial da mensagem se concentra na explicitação da data. É o que se observa em algumas cartas de Juliette Drouet dirigidas a Victor Hugo, dentro da correspondência que durou 50 anos, de I833 a I883. Juliette Drouet escreveu mais de 20 mil cartas a seu ilustre amante para lhe assegurar que seu amor se mantinha sempre inabalável. No final da vida em comum, quando as crises que abalaram o casal se amenizaram, só o vínculo epistolar contava. A correspondência esvaziou-se das anedotas, resumindo-se à repetição performativa do "eu te amo". Exemplo disso, essas linhas escritas numa sexta-feira, 6 de março de I874, às II horas da manhã, em que Juliette mostra-se esperançosa de fazer, eventualmente, um passeio com seu querido "Toto":

Amo-te a velas desfraldadas, meu querido adorado, o que me dá o desejo desenfreado de perder-me a teu lado, bordejando a primavera, as flores e a vida se renovando pelo tempo que minhas pernas hoje puderem me sustentar. Mas para tanto precisarias cometer uma grave infração nos teus hábitos de trabalho, almoçando um pouco mais cedo. Conseguirias? Duvido (diante da rainha!). Mas bastaria aprovares os planos dessa louca aventura para deixar-me completamente feliz. Como será então se realmente quiseres realizá-la? Enquanto aguardo, preparo-me para qualquer eventualidade: conformar-me se não puderes sair comigo ou agarrar a felicidade se, como espero, consentires em jogar tua pluma ao vento por algumas horas. O que quer que faça ou o que quer que aconteça, adoro-te?.

Inserir a data confere plena existência ao manuscrito autógrafo. À carta remetida a um correspondente - mas também lançada, se for conservada, na longa viagem da posteridade - a data concede uma espécie de passaporte, uma autorização para circular, que lhe garante um feliz encaminhamento. Do uso indiscreto que mais tarde poderia ser feito pela posteridade, Zola tinha plena consciência, como o ilustra a declaração dada a um jornalista numa entrevista em I896:

Alguns homens poderão se sentir denegridos pela publicação de seus escritos mais íntimos, mas azar deles! Cartas encontradas, e depois reunidas em livros, seus autores sabem muito bem de sua existência; se não as destruíram, é porque não se sentiam incomodados com o fato de que a família ou os amigos as descobririam, leriam e talvez viessem a publicá-las. Cabe ao autor prever e destruir tudo o que não deseja que se conheça sobre ele ${ }^{8}$.

7 DROUET, Juliette apud HEUTE, Véronique. Édition critique des lettres de Juliette Drouet à Victor Hugo de I874-I875. [Edição crítica das cartas de Juliette Drouet a Victor Hugo.] Tese de doutorado. Orientadores: Florence Naugrette e Jean-Marc Hovasse. Paris: Université Paris 3-Sorbonne, 20I7, p. 224.

8 ZOLA, Émile apud Nouvelle Revue Internationale, I5 de julho de I896 (artigo posteriormente reproduzido no Mercure de France, Iํำ de abril de I928, p. 254). 
O editor moderno só tem a agradecer aos escritores - a posteriori - pelo cuidado que tiveram ao datar suas cartas autógrafas antes de enviá-las. Talvez possa enxergar nesse fato uma autorização dada àquele para que proceda à paciente exumação necessária para sair de uma zona nebulosa e publicar os documentos às claras.

\section{A ASSinatura}

Zola assinou praticamente todas as suas cartas, servindo-se de uma assinatura que pouco variou da juventude à maturidade: nome seguido pelo sobrenome, formando ambos um bloco indissociável. Veja-se a assinatura com a qual encerra a carta dirigida a Georges Charpentier, em 2 de dezembro de I884. É um desenho: as curvas que formam as letras "E" e "Z" se interligam, enquanto a letra "a" final se prolonga num traço ondulado que repete a forma do " $Z$ " central.

Zola compreendeu bem cedo a sorte que o destino lhe reservara dotando-o de um nome que começava pela letra $\mathrm{Z}$ e terminava pela letra A. Bastava-lhe, pois, cumprir o programa contido em tal patronímico: contemplar o mundo com um olhar enciclopédico, tudo ver e tudo conhecer, escrever de A a Z... O escritor se beneficiava de um privilégio que, antes dele, só conhecera aquele que se tornaria seu modelo na escrita dos ciclos dos Rougon-Macquart: Balzac, cujo sobrenome continha a mesma aliança predestinada, "ZA".

A assinatura constante representa, no caso de Zola, uma característica que merece ser destacada. Na mesma época, seus contemporâneos raramente mantêm a mesma fidelidade gráfica quando transcrevem seu patronímico. Naturalmente, várias práticas podem ocorrer simultaneamente, não existe regra absoluta, porém é possível observar variações expressivas. Hugo, por exemplo, assinava tanto "Victor Hugo" como "Victor H., "V. H.", ou "V". Quando escrevia a Juliette Drouet, terminava sempre com "Victor", "V", ou simplesmente se abstinha de qualquer indicação. Maupassant, em geral, assinava "Guy de Maupassant”, mas por vezes se contentava com "Maupassant”; nas cartas aos amigos da juventude, usa seu primeiro nome (“Guy", “Guitte”), ou, por diversão, emprega seu pseudônimo (“Joseph Prunier", "Prunier"). Mas foi, sem dúvida, Flaubert quem se mostrou mais criativo. Regra geral, ele assinava "Gve Flaubert", porém suas cartas, especialmente na última parte de sua vida, oferecem uma grande variedade de fórmulas. As assinaturas são personalizadas em função do destinatário: "Votre Vieux" (a Tourguéniev ou a Maupassant, em I878-I879), "Votre Géant" (a Edmond Laporte, na mesma época), "Ton vieil oncle", "Ta vieille nounou", "Vieillard de Cro-Magnon" (a sua sobrinha Caroline) etc.

No conjunto da correspondência de Zola, a ausência de assinatura ocorre em duas situações: nas cartas a Jeanne Rozerot, nas quais as assinaturas aparecem muito raramente; e nas cartas escritas durante o exílio na Inglaterra, entre julho de I898 e junho de I899. Durante esse período, Zola receia ser alvo de perseguições judiciais e toma todo tipo de precaução para impedir que sua correspondência seja interceptada. Ocultar o sobrenome faz parte dessas medidas. Quanto às cartas enviadas a Jeanne Rozerot, o silêncio gráfico sugere diversas interpretações: afirmação de uma proximidade amorosa que dispensa qualquer identificação pessoal? Ou ainda 
tratamento especial dado a uma relação que, embora não fosse escondida, pode ao menos permanecer protegida do olhar da sociedade? Desse ponto de vista, as duas partes da correspondência íntima não atribuem a mesma função à assinatura. As cartas a Alexandrine são todas assinadas (exceto durante o exílio) e se encerram com a proclamação de um nome de escritor. Nesse sentido, as missivas afirmam a necessidade dessa obra epistolar sobre a qual se apoia o pacto moral que permite ao casal manter-se unido, apesar das adversidades. Por outro lado, as cartas destinadas a Jeanne repousam sobre outra forma de relação na qual a notoriedade literária ocupa um lugar bem mais reduzido: o escritor é, acima de tudo, o amante e o pai de duas crianças, nascidas de uma união estabelecida fora das convenções sociais.

Embora privadas de qualquer tipo de assinatura, as cartas do exílio não terminam com um vazio gráfico. Na parte inferior dos textos, encontra-se um estranho traço arqueado, como se fosse um $Z$ esmagado, riscado na horizontal. A interrupção brutal da escrita era impossível. Era preciso um fecho, uma marca de conclusão, uma pontuação gráfica, função que seria cumprida por aquele traço.

O mesmo tipo de pontuação é encontrado nos dossiês preparatórios do escritor que intervêm em momentos-chave da construção da intriga quando o romancista consegue resolver problemas nos quais tropeçava. Colette Becker propõe a seguinte análise:

Alguns sinais presentes nas assinaturas, como aquela letra Z parcialmente discernível, denotam a satisfação de Zola [com o resultado de seu trabalho]. Aparecem no final de algumas cenas, em geral de sexo e sangue, que agradavam ao escritor. É o que acontece no dossiê de Germinal, no final dos segundos planos de cinco capítulos que encerram momentos especialmente dramáticos. [...] Esse mesmo traço de satisfação está presente em partes da redação do final do capítulo IX de $O$ paraíso das damas: é bem provável que Zola tenha ficado muito satisfeito por ter conseguido impedir a personagem Denise de ceder aos avanços de seu patrão. Mesma prova de contentamento se observa no final do segundo plano do último capítulo de Pot-Bouille [A roupa suja], cujo desfecho o romancista encontrara ou estava prestes a encontrar. [...] Ou ainda no dossiê de L'CEuvre [A obra], depois da primeira cena de amor entre Claude e Christine, ou ainda quando os personagens deixam definitivamente sua casa no campo para retornar a Paris etc. Em suma, esses traços pontuam momentos de forte carga emocional.

\section{A PERIFERIA}

O cabeçalho ou as margens constituem as zonas periféricas que as edições impressas frequentemente ignoram na apresentação que oferecem do texto de uma correspondência, apagando-os ou neutralizando-os. Porém, a essa periferia se prende um significado que a contemplação do manuscrito autógrafo torna explícita.

9 BECKER, Colette. Le langage silencieux des manuscrits zoliens. In: Le réalisme et ses paradoxes (I850-I900). Direction de Gabrielle Chamarat et Pierre-Jean Dufief. Paris: Classiques Garnier, 20I4, p. 435-436. 
Tome-se como exemplo a carta enviada pelo jovem Zola a Émile Deschanel, em 26 de novembro de I864 (Figura 4).

UBRAIRIE DE L. HACHETTE, ET C", BOULEVARD SAINT-GERMAIN, 77

Ravis, le 26 nor. 64

Chor monieus

Mont a que vomeferes, rera bui fait. I. in in jancui olonts de Notre obliycance a mou éard, et: rais yeu vous me obuneres $h$ phu do place you vour pourres.

If neyratt de vou inforturer on la rorts. A mom age, on cit äpre a la curé, thon n'a prar de pitic pour les puistant. fordoung nea.

Waillez cyreir, do vou fric, P'arcerara of wer ratiments recounairsants t devoner.

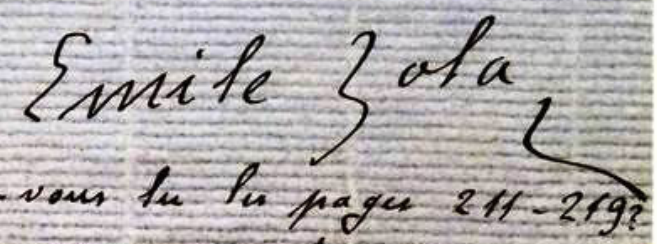

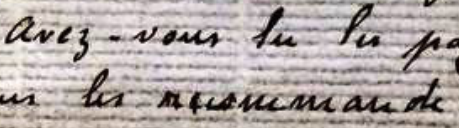

Figura 4 - (c) Coleção particular (carta inédita)

II8 [

revista do Instituto de Estudos Brasileiros · n. 67 • ago. 2017 (p. IO6-I23) 
Cher monsieur,

Tout ce que vous ferez, sera bien fait. Je n'ai jamais douté de votre obligeance à mon égard, et je sais que vous me donnerez le plus de place que vous pourrez.

Je regrette de vous importuner de la sorte. À mon âge, on est âpre à la curée, et on n'a pas de pitié pour les puissants. Pardonnez-moi.

Veuillez agréer, je vous prie l'assurance de mes sentiments reconnaissants et dévoués.

Émile Zola

Avez-vous lu les pages 2II-2I9? Je vous les recommande.

[Prezado senhor,

Tudo o que fizer estará bem-feito. Eu nunca duvidei de sua benevolência para comigo, e sei que o senhor me dedicará todo o espaço que lhe for possível.

Lamento importuná-lo dessa forma. Na minha idade, somos intransigentes com a avidez, e não temos piedade dos poderosos. Perdoe-me.

Queira aceitar, por obséquio, a garantia dos meus sentimentos de gratidão e devotamento.

Émile Zola

O senhor leu as páginas 2II-2I9? Recomendo-as].

Em I864, Zola tem 24 anos e trabalha numa editora, Maison Hachette, onde se encarrega do setor de publicidade. Seu primeiro livro, Contes à Ninon, acabava de ser publicado. Ele enviou um exemplar ao crítico do Journal des Débats, Émile Deschanel, na esperança de ser resenhado. Deschanel é uma das personalidades mais influentes do momento. Zola se dá ao trabalho de indicar uma passagem importante situada no final do volume, num conto filosófico à moda de Voltaire, "Les Aventures du grand Sidoine et du petit Médéric" ("As aventuras do grande Sidoine e do pequeno Médéric”). Como bom estrategista de publicidade editorial, o escritor antecipa a maneira como o crítico fará a leitura de sua obra. É a parte central da mensagem que mais chama a atenção: "Na minha idade, somos intransigentes com a avidez, e não temos piedade dos poderosos. Perdoe-me”. Ao mesmo tempo que se desculpa pela ousadia da solicitação feita a Deschanel, Zola expressa sem rodeios a ambição que o anima. Mas o que lhe inspira tal audácia? Sem dúvida, o cabeçalho "Librairie de L. Hachette”, impresso em letras capitais, no alto da página. Não é possível compreender a liberdade de tom empregada na carta se não levarmos em conta a aura conferida a sua mensagem pela força do nome Hachette, por trás do qual o jovem escritor se abriga.

Veja-se agora a última página de uma carta a Alexandrine, escrita em I8 de dezembro de I898 (Figura 5), durante o exílio na Inglaterra (a assinatura se reduz a uma vaga letra $\mathrm{Z}$ ). 
- Ln ivinamente un intiressent bauconpendi

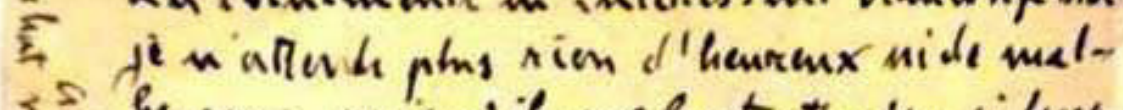
5.5 havemx, piniqu' if me fant at/ardre si long S. tempn. Et f prisque $j^{\prime}$ amis un éponvantere $\Rightarrow$ prisqu or ue clit thi natemmtqu'un Fon a pas bosoin de moins, quion in'onth

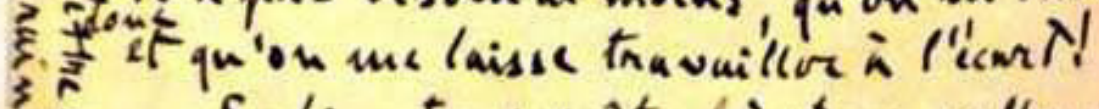
Enfin. Th was itre lis ct nous allons है: repromilse nothe vis dicalme, trop onlms,

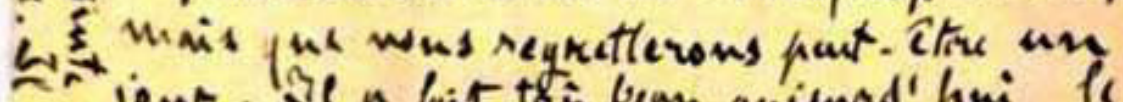

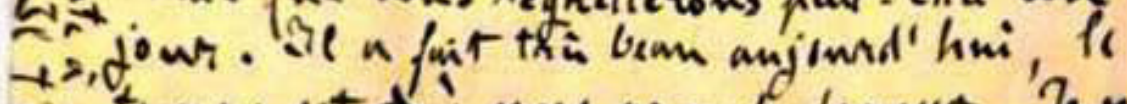

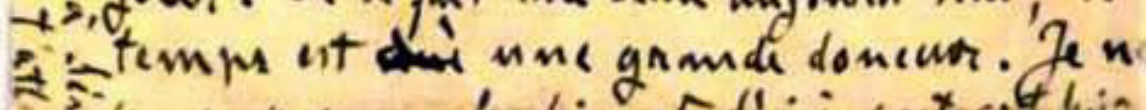

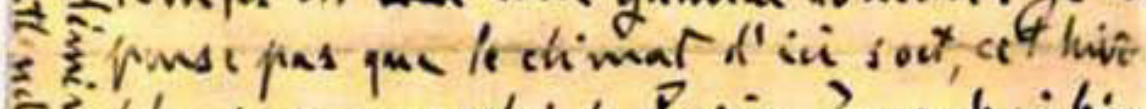

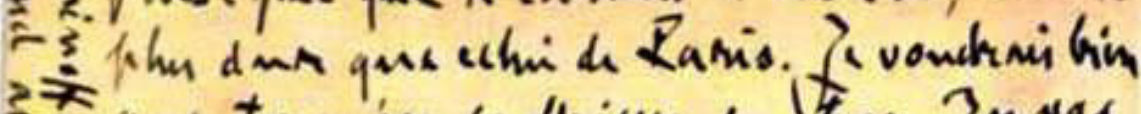
Ei que tun in soup/priss pas trop. In vas E.'voir comme nons scrons paisithe, dis que i : nons aurous repria nos petites hatitudes,

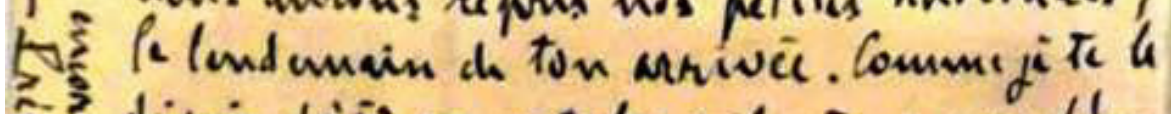

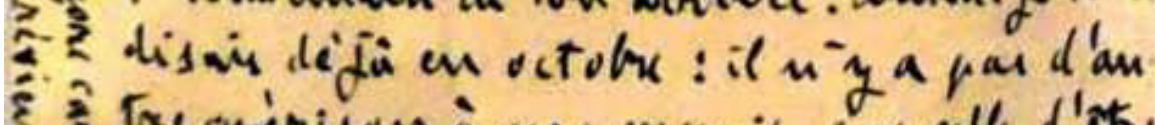
¿ Treguinison à nos ennisi, que called'the

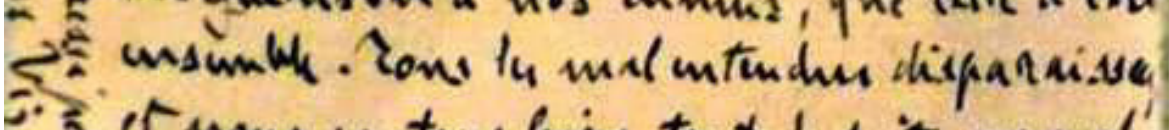
ct nons suntons bien tont de wits qui mal' E. Eprofouds affection. ('ut un grand sonla ganum

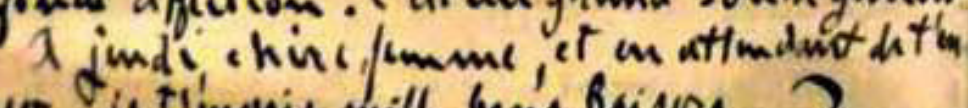

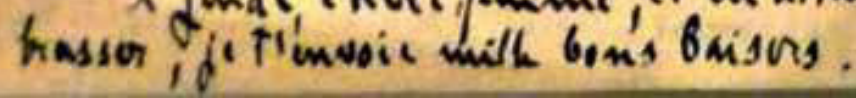

Figura 5 - (c) Centro Zola, Item, CNRS

I2O [

revista do Instituto de Estudos Brasileiros • n. 67 • ago. 2017 (p. Io6-I23) 
Les événements m'intéressent beaucoup moins, je n'attends plus rien d'heureux ni de malheureux, puisqu'il me faut attendre si longtemps. Et, puisque je suis un épouvantail, puisqu'on me dit très nettement qu'on n'a pas besoin de moi, qu'on m'oublie et qu'on me laisse travailler à l'écart!

Enfin, tu vas être là et nous allons reprendre notre vie si calme, trop calme, mais que nous regretterons peut-être un jour. Il a fait très beau aujourd'hui, le temps est d'une grande douceur. Je ne pense pas que le climat d'ici soit, cet hiver, plus dur que celui de Paris. Je voudrais bien que tu n'en souffrisses pas trop. Tu vas voir comme nous serons paisibles, dès que nous aurons repris nos petites habitudes, le lendemain de ton arrivée. Comme je te le disais déjà en octobre: il n'y a pas d'autre guérison à nos ennuis, que celle d'être ensemble. Tous les malentendus disparaissent et nous sentons bien tout de suite que, malgré tout, nous avons gardé l'un pour l'autre la plus profonde affection. C'est un grand soulagement.

À jeudi, chère femme, et en attendant de t'embrasser, je t'envoie mille bons baisers.

[Na margem] Adresse la lettre ci-jointe à Séménoff. - J'ai encore caressé pour toi le chat noir des grainetiers. Il t'attend aussi. - Préviens Vizetelly.

[Os acontecimentos me interessam muito menos, nada espero de feliz nem de infeliz, já que preciso esperar muito tempo. E, já que sou um espantalho, já que me dizem claramente que não precisam de mim, então que me esqueçam e me deixem trabalhar sozinho.

Enfim, estarás de volta e vamos retomar nossa vida calma, bem calma, mas da qual talvez um dia sentiremos saudade. Hoje o dia está lindo, o tempo é bastante ameno. Não creio que o clima daqui, neste inverno, seja mais inclemente do que o de Paris. E eu gostaria muito que não sofresses tanto com isso. Verás como ficaremos tranquilos, assim que pudermos retomar nossos pequenos hábitos, já no dia seguinte da tua chegada. Como já te escrevi em outubro: não há melhor cura para os nossos problemas do que estarmos juntos. Todos os mal-entendidos desaparecem e sentimos num instante que, apesar de tudo, conservamos o mais profundo afeto um pelo outro. É um grande alívio.

Até quinta-feira, querida esposa, e, enquanto espero poder abraçá-la, envio-lhe mil beijos.

[Na margem] Envie a carta anexa a Séménoff. - Acariciei novamente por ti o gato dos vendedores de grãos. Ele também te aguarda. - Avise Vizetelly].

Nas quatro páginas da carta, as informações se acumularam. Chegando à última etapa de sua progressão e também ao cabo do esforço, a escrita se comprime, as palavras se apertam para dizer quão mais for possível, ocupando todo o espaço disponível. Mas isso não basta, e o escritor acaba usando a margem para inserir as últimas informações, em duas linhas verticais: "Adresse la lettre ci-jointe à Séménoff. - J'ai encore caressé pour toi le chat noir des grainetiers. Il t'attend aussi. - Préviens Vizetelly”. Tudo se atropela em algumas palavras: uma carta a ser enviada a um amigo, o jornalista russo Eugène Séménoff; a necessidade de avisar Ernest Vizetelly, o tradutor inglês, que cuida dos negócios de Zola em Londres; e essa última mensagem de afeto dirigida à figura ausente ("J'ai encore caressé pour toi le chat noir des grainetiers"), lembrando as semanas que a esposa havia pouco 
passara ao seu lado, e colocando-se à espera da próxima viagem que promoverá o reencontro do casal.

A edição de uma correspondência é tensionada por dois objetivos contraditórios: por um lado, o dever intelectual, que consiste em oferecer ao público um texto legível, uniformizado, livre de eventuais imperfeições; por outro, a necessidade de conservar, tanto quanto possível, a mensagem contida nos manuscritos autógrafos. Quando o editor dispõe do direito de reprodução dos documentos originais, a maneira de resolver tal contradição passa pela reprodução de fac-símiles, ou pela escolha de uma edição eletrônica, oferecendo a visualização tanto do texto editado quanto da imagem do manuscrito.

Em conclusão, desejamos chamar a atenção para esse objeto preciosíssimo, a carta autógrafa, cujo formato, aparência gráfica e a própria fragilidade provocam uma emoção imensa naqueles que a contemplam ou a seguram nas mãos. Todas as bibliotecas conservam coleções que possuem múltiplos tesouros. Seria uma lástima permitir que os arquivos abertos da internet nos afastassem, hoje, pela facilidade de consulta, desses inúmeros arquivos que escapam à digitalização e obrigam o pesquisador a se deslocar, mas que lhe oferecem o privilégio de ter acesso a documentos raros e totalmente desconhecidos.

\title{
SOBRE O AUTOR
}

\author{
ALAIN PAGÈS é professor de Literatura Francesa \\ da Université Sorbonne Nouvelle Paris 3 e \\ responsável pela equipe Zola do Institut des \\ Textes et Manuscrits Modernes - Item. \\ E-mail: alain.pages@univ-paris3.fr
}

\section{REFERÊNCIAS BIBLIOGRÁFICAS}

BECKER, Colette. Le langage silencieux des manuscrits zoliens. In: Le réalisme et ses paradoxes (I850-I900). Direction de Gabrielle Chamarat et Pierre-Jean Dufief. Paris: Classiques Garnier, 20I4, p. 435-436. HEUTE, Véronique. Édition critique des lettres de Juliette Drouet à Victor Hugo de I874-I875. [Edição crítica das cartas de Juliette Drouet a Victor Hugo.] Tese de doutorado. Orientadores: Florence Naugrette e Jean-Marc Hovasse. Paris: Université Paris 3-Sorbonne, 20I7, p. 224.

LABADENS, François. Cet obscur objet du désir. Propos d'un amateur d'autographes. [Este obscuro ob- 
jeto do desejo. Entrevista com um amante de manuscritos autógrafos.] In: L'entreprise et sa mémoire. Mélanges en l'honneur de Maurice Hamon. Organização de Didier Bondue. Paris: Presses universitaires de Paris-Sorbonne, 20I2, p. 236.

NOUVELLE Revue Internationale, I5 de julho de I896 (artigo posteriormente reproduzido no Mercure de

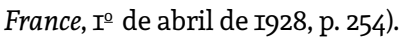

ZOLA, Émile. Correspondance. [Correspondência.] Organização de Bard H. Bakker. Montréal: Les Presses de l'Université de Montréal; Paris: Éditions du CNRS, I978-I995, Io v.

. Lettres à Jeanne Rozerot. [Cartas a Jeanne Rozerot] (I892-I902). Edição preparada por Brigitte ÉmileZola e Alain Pagès. Paris: Gallimard, 2004.

. Correspondance XI. Lettres retrouvées (I858-I902). Apresentação de Owen Morgan e Dorothy E. Speirs. Montréal: Les Presses de l'Université de Montréal; Paris: CNRS Éditions, 2010.

. Lettres à Alexandrine [Cartas a Alexandrine] (I876-I9OI). Edição preparada por Brigitte Émile-Zola e Alain Pagès. Paris: Gallimard, 20I4. 